\title{
Analysis of the Impact of Health Communication on Prevention and Control Behaviors and Awareness Among Shanghai Residents in the Background of the COVID-19
} A Perspective Based on the Theory of Planned Behavior

\author{
Shijie Huang, ${ }^{1, *}$ \\ ${ }^{1}$ School of Shanghai University Of Engineering Science, Shanghai, China \\ *Corresponding author Email: guanghua.ren@gecacademy.cn
}

\begin{abstract}
At the end of 2019, the COVID-19 broke out in inland China, and the outbreak gradually spread worldwide. In prevention and control, the public's attention to this epidemic has increasingly grown and their demands for various types of information have shown an upward trend. The Medium Effect of Health Communication plays a vital role in the prevention and control of this epidemic. Shanghai, however, as one of the most densely populated cities and one of the most susceptible to outbreaks of the virus, has yet demonstrated excellent control effects. To study the impact of Health Communication on the prevention and control behaviour and awareness of Shanghai residents in the context of the COVID-19, this paper is based on The Theory of Planned Behavior (TPB) and actual data. Then, it is found that three factors are the crucial points in the role of Health Communication in the prevention and control of the COVID-19 in Shanghai. They are residents' attitudes towards collecting epidemic prevention information, friends' and relatives' attention to epidemic prevention information and ease of access to epidemic prevention information. In addition, these three factors can be addressed individually to improve the effectiveness of the prevention of the disease in the area. For example, the official media can engage the public by increasing entertaining and innovation in the dissemination of epidemic prevention information. The government can enact relevant laws and regulations to force people to implement epidemic prevention and control measures. Raising the frequency of Health Communication is an outstanding method as well. All in all, by studying Shanghai residents' behavior and awareness of epidemic prevention, this article will provide a reference for people all over the world to fight the COVID-19.
\end{abstract}

Keywords: Theory of Planned Behavior, Health Communication, the COVID-19(2019-nCoV).

\section{INTRODUCTION}

The outbreak of the 2019 Corona-virus disease (COVID-19, hereafter referred to as New Corona virus Pneumonia) caused by Severe Acute Respiratory Syndrome Corona-virus 2 (SARS-CoV-2) was initially identified in Wuhan, China, in December 2019. Within approximately one month, the outbreak created an epidemic throughout China [1]. The new Corona-virus spread rapidly to other Asian countries within three months and subsequently spread worldwide. On 11 March 2020, the World Health Organization (WHO) declared COVID-19 a global pandemic [2]. According to official figures reported by the World Health
Organization, in mid-April 2021, the cumulative number of confirmed cases of COVID-19 worldwide exceeded 140 million, causing approximately 3 million deaths in all countries worldwide. The data shows that India, Brazil, the United States, Turkey and France are the five countries with the highest number of new confirmed cases. Brazil, India, the United States, Poland and Mexico are the five countries with the highest number of recent deaths.

In China, according to public data from the National Health Commission, as of April 2021, the cumulative number of confirmed cases in China was about 100,000, about $1 / 30$ of the global number of infections, and the 
cumulative number of deaths was less than 4,900. Since China lifted its 76-day blockade of Wuhan on 8 April 2020 , the country has worked to contain the outbreak and has succeeded in stopping the rebound and importation of new cases. Social and economic life in China has been gradually recovering. Although some areas have since seen sporadic cases of COVID-19 influenced from outside of the border, the domestic outbreak is mainly under control.

In Shanghai, according to public data from Shanghai Health Care Commission, as of April 2021, there were a cumulative total of 1,940 confirmed cases and seven deaths. Shanghai is a mega-city with 24 million, including a foreign population of nearly 10 million. The early stages of the outbreak were during the Chinese New Year when Shanghai had a massive advantage in controlling the epidemic as many migrant workers returned home for the New Year, and the population flowed out. However, after the Spring Festival, when the epidemic was at its worst, nearly 8 million people returned to Shanghai to work. This massive population swells dramatically increases the difficulty of preventing and controlling the epidemic. Consequently, for a megacity of 24 million people, the infection and mortality rates in Shanghai are undoubtedly remarkable compared to the overall international environment. In addition to proper management decisions by the government, the active cooperation of the public is also crucial to the success.

Since the outbreak of the COVID-19, it has rapidly attracted significant attention both at home and abroad. The prevention and control of the epidemic have been one of the concerns of the health and epidemic prevention departments. People often obtain information about epidemic prevention through media channels such as television and the internet, which enhances their awareness, reduces the chance of infection, and effectively prevents the spread of infectious diseases [3]. In the early stages of a disease outbreak, the authorities should firstly raise Health Communication efforts according to the severity of the spread of the disease, so that awareness of the disease gradually will increase in people's minds. Secondly, individuals should cooperate with the authorities in taking preventive measures. In this way, to some extent, the number of infected people will tend to grow slowly. For example, at the beginning of the SARS outbreak in 2003, people were informed about the mode of infection, the incidence of the illness, and preventive measures through various methods such as leaflets, community consultations, and media coverage. An epidemiological survey of 3405 people in one area found that the awareness rate of SARS was over 95\% [3].

It is often assumed that the level of health care in the country, the government's management practices and people's self-prevention measures are the main factors that make it possible to effectively control the epidemic in the country, but few studies have considered 'Health
Communication' to be an influential factor as well. After the episode of the COVID-19 in early 2020, some people did not understand how to prevent and control this epidemic; some people were not aware of the seriousness of this epidemic and did not cooperate in taking preventive measures, and others became nervous and anxious due to rumors. In this era of Convergence Media, in addition to mainstream media reporting on the frontline of the epidemic, medical and health media, with their professional medical background and various social media platforms, have featured prominently in popularizing the epidemic alleviating anxiety, and combating rumors.

\section{LITERATURE REVIEW}

\subsection{Theory of Planned Behavior}

The Theory of Planned Behavior (TPB) was developed by Ajzen (1985) and evolved from the Theory of Reasoned Action (TRA) proposed by Fishbein \& Ajzen in 1975. The theory suggests that the three variables of Attitude, Subjective Norm and Perceived Behavioral Control determine an individual's Behavioral Intention. Behavioral Intention determines an individual's behavior and Behavioral Intention in terms of the way it works: Attitudes, Subjective Norms and perceptions of behavioral control [4]. The theory has been successfully applied to explain and predict a wide range of human behavior.

\subsection{Health Communication}

In 1971, the Stanford Heart Disease Prevention Program in the United States first applied communication to the field of health. In the 1980 s, research aimed at AIDS prevention gave a strong impetus to the development of Health Communication. 1994, Rogers believed that Health Communication is the translation of medical research findings into health knowledge that is readily accepted by the general population, and the recipients can change their attitudes and behavior to reduce mortality and disease, thus improving the quality of life and health standards of the recipients. In 1996, Chinese scholars proposed that Health Communication is acquiring, producing, communicating. and analyzing health information through various communication media, with the health of all people as the starting point and purpose [5].

The concept of Health Communication can be defined in two ways: firstly, in a broad sense, Health Communication covers a wide range of topics, including not only mass communication, but also organizational and interpersonal communication, and involves a variety of issues; secondly, in a narrower sense, it focuses on the effectiveness of Health Communication from the perspective of communication strategy, aiming to 
Secondly, the more limited concept focuses on the efficacy of Health Communication, aiming to change attitudes and thus behavior through persuasion [6].

\subsection{Health Communication}

In the context of the COVID-19 epidemic, there is a relative lack of research in China to analyze the effect of Health Communication on prevention and control behaviors and awareness among Shanghai residents. The communication methods they studied were broadly divided into Mass Media, New Media, and Self-Media. The study groups are mostly separate from university students or middle-aged and older people.These studies have indicated that health-related media have significant effects on people's perceptions, attitudes and behaviors. Simultaneously, the content of epidemic prevention information and the frequency of users' likes, following and re-tweeting remarkably influence the effectiveness of Health Communication during epidemics. In the social context, it cannot be ruled out that public health emergency contributes to Health Communication effects and that effects possess possible time-sensitive.

One of a survey revealed that, in terms of healthrelated We-Chat Public, although the effect of Health Communication in university students is noticeable, there are still some shortcomings need to be further improved, such as low quality of content, lack of professionalism and the governance of rumors [7].

Compared to the communication effect of public websites, there is still much room to explore the quality and depth of knowledge, the relevance of the posting and the expression of the content in new media short videos that disseminate information. Research shows that new media short videos should strengthen their content construction, maintain credibility and create in-depth and original content when disseminating health information. When producing short video content, health knowledge should be combined with daily life practices, and knowledgeable expressions should be revitalized with everyday language so that elite content can be popularized and professionalism can be brought closer to everyday life, making it more accessible to the general public. At the same time, it has been suggested that when major public health emergencies occur, people's need for information changes due to threats to their safety. In contrast, the mainstream media has limited knowledge due to platform limitations or other reasons, and audiences have to turn to other channels to obtain information. The profound impact of new media communication on major public emergencies shows that early observation and intervention before the golden four hours, an optimal time frame for coverage, is an effective way to prevent large swings in social sentiment and mitigate negative public opinion clusters [8].
Compared to the first two methods of communication, the survey found that Public Service Announcements during the epidemic broke away from the traditional techniques and produced many innovative ways of communication, playing an extremely crucial role in the national response to the crisis. When studying the effectiveness of Public Service Announcements, it is significant to use short, vibrant and dynamic videos to convey the message as much as possible, because dynamic videos are more likely to attract attention, especially from older people or younger children who are less likely to remember text or static images. Secondly, attention should be paid to choosing a more timely and authentic approach, prioritizing online live streaming and video-based timely releases. Finally, emphasis should be placed on using graphic ideas to attract people's attention and achieve a quick and intuitive information delivery. Especially when people are in a hurry to pass by outdoors, Public Service Announcements need to allow people to receive the appropriate information visually and quickly through their straightforward content in a flash [9].

In contrast to the effects of transmission among adolescents, studies have shown middle-aged and older people excessively rely on experience, so that they tend to be less vigilant about epidemic prevention. In other words, this group are likely to increase the spread of the epidemic, because they often underestimate the dangers of a new disease and fail to protect themselves. In addition, the media literacy of the middle-aged and elderly is more underdeveloped than that of young people. It prevents them from accessing information on the internet as quickly as young people and from accurately understanding what is going on and the importance of what is going on, so they did not initially understand the dangers of the virus clearly and accurately during the Newcastle pneumonia outbreak. It also shows that there is an urgent need for the media and related science organizations to use folklore to communicate science effectively, transforming the difficult medical language into a folklore language that can be accepted by the public, which will help to communicate more effectively between the two generations [10].

Unlike domestic outbreaks, studies of outbreaks in foreign regions have shown that people who are less vigilant about vaccination are not limited to the middleaged and elderly population. Although many people are concerned about the possibility of contracting COVID19 , few consider themselves to be at high risk of being infected by COVID-19 [11]. It suggests that raising public awareness of the risks is critical, depending on the country's characteristics.

This paper will analyze and process the collected data based on the Theory of Planned Behavior. In exploring the effect of Health Communication on the prevention and control behavior and awareness of Shanghai residents, this study will use the attitude of Shanghai 
citizens towards learning about the prevention and control of COVID-19 as a subjective attitude variable. In other words, citizens are motivated to learn about the disease and find the helpful knowledge; the knowledge and practice of their relatives and friends around them about the prevention and control of the disease as an individual subjective attitude variable; and whether citizens take preventive measures after learning about the disease, such as citizens can wear masks in public and wash their hands regularly, to examine their behavioral awareness. The extent of citizens' behavioral awareness is reviewed in terms of whether they take preventive measures after learning about epidemic prevention. For example, citizens can wear masks in public and wash their hands regularly. The influencing factors are as follows: the age of people, the richness of the content, and form of Health Communication.

By studying the impact of Health Communication on the prevention and control behavior and awareness of Shanghai residents in the context of the new epidemic, it is possible to understand whether Health Communication can increase people's understanding of the epidemic and whether there is a disconnect between knowledge and action. Which groups of people are more likely to be affected by Health Communication? How does it affect the remaining population? Given this, the study uses the Theory of Planned Behavior as a guide to explore how to improve the effectiveness of Health Communication and thus provide a sample value for people worldwide to "fight the epidemic".

This paper adopts a questionnaire-based research approach, based on the Theory of Planned Behavior, and raises explicitly the following hypotheses:

Hypothesis 1: The extent to which citizens are exposed to knowledge about epidemic prevention will significantly impact the adoption of epidemic prevention behavior by citizens.

Hypothesis 2: Citizens' attitudes and concerns about knowledge of epidemic prevention are positively associated with citizens' adoption of epidemic prevention behaviors.

Hypothesis 3: There is a significant effect between the level of concern of citizens' friends and relatives for information on epidemic prevention and how citizens will adopt epidemic prevention measures.

\section{METHODOLOGY}

The questionnaire method is one of the more widely used methods in social surveys, both domestically and internationally. A questionnaire is a form used for statistical and survey purposes that formulates questions in a set of questions. The questionnaire method is a way for the researcher to collect reliable information by using this controlled measure of the problem under study [12].

The questionnaire was distributed and collected using the Questionnaire Star, a data collection platform in China. 34 questions were divided into 7 main categories using the Richter scale. They are attitudes to information about epidemic prevention, citizens' responses to subjective norms, perceived control of behavior to knowing about information about epidemic prevention, levels of knowledge of the effective epidemic prevention behavior, and levels of concern, trust and preference for different ways of accessing information about disease prevention. To be scientific and to ensure the accuracy of the results, the questions were designed to cover as many factors as possible that influence citizens in their daily lives.

The questionnaire was distributed in March 2021 and was collected over two weeks. The questionnaire was screened to ensure the collected data consistent with the topic of the study by setting a question: whether you have lived in Shanghai for one year or more. It was estimated that 400 questionnaires would be collected, but 387 questionnaires were collected actually, and 365 valid questionnaires were obtained after the screening process. To correspond to the four essential elements of the theory of Planned Behavior, namely attitude, subjective norm, perceptual control of conduct and behavioral awareness, this study focused on the four essentials elements which are attitudes to information about epidemic prevention, citizens' responses to subjective norms, perceived control of behavior to knowing about information about epidemic prevention, levels of knowledge of the effective epidemic prevention behavior, and levels of concern for different ways of accessing information about disease prevention. The data from the four Richter scales were integrated and analyzed using Pearson's correlation analysis in SPSS. The results show the relevance of attitudes, subjective norms and perceptual control of behavior to the adoption of behavior. Then we can know how citizens can be motivated to adopt more effective preventive measures by Health Communication. This study shows that attitudes, subjective norms and perceived behavioral control are relevant to the adoption of epidemic behavior. The data not be utilized in this study will be used as a sample to support in-depth research in this area in the future. 


\section{RESULT}

\subsection{Hypothesis 1}

Table 1. Data coding for hypothesis 1

\begin{tabular}{|c|c|c|c|c|}
\hline $\begin{array}{l}\text { Title: } \\
\text { To what extent } \\
\text { do you agree } \\
\text { with }\end{array}$ & Strongly disagree and disagree & $\begin{array}{l}\text { Agree } \\
\text { and } \\
\text { strongly agree }\end{array}$ & $r$ & $p$ \\
\hline $\begin{array}{l}\text { Easily from } \\
\text { the community }\end{array}$ & $4.11 \%$ & $81.09 \%$ & 0.418 & .000 \\
\hline $\begin{array}{l}\text { Easily from } \\
\text { mobile social } \\
\text { media platforms }\end{array}$ & $1.92 \%$ & $90.41 \%$ & 0.505 & .000 \\
\hline Easily from TV & $2.74 \%$ & $87.4 \%$ & 0.425 & .000 \\
\hline $\begin{array}{l}\text { Easily from } \\
\text { newspapers and } \\
\text { magazines } \\
P<0.05 P<0.01 \mathrm{~F}\end{array}$ & $9.68 \%$ & $78.36 \%$ & 0.376 & .000 \\
\hline
\end{tabular}

Using Pearson's correlation coefficient analysis, the results of the study showed that there are the awareness of epidemic-related knowledge seen in the community $(\mathrm{r}=0.418, \mathrm{P}=0.000<0.001)$; the awareness of epidemicrelated knowledge obtained from mobile social media platforms $(\mathrm{r}=0.505, \mathrm{P}=0.000<0.001)$; the awareness of epidemic-related knowledge seen on television $(\mathrm{r}=0.425$, $\mathrm{P}=0.000<0.001)$; and the publicity of epidemic prevention-related knowledge from newspapers and magazines $(\mathrm{r}=0.376, \mathrm{P}=0.000<0.001)$ have a significant positive correlation on citizens' adoption of epidemic prevention behavior. In result, the greater the degree of citizens' exposure to epidemic prevention knowledge, the more likely citizens will adopt epidemic prevention behavior. Consequently, the original hypothesis is valid.

\subsection{Hypothesis 2}

Table 2. Data coding for hypothesis 2

\begin{tabular}{|c|c|c|c|c|}
\hline $\begin{array}{l}\text { Title: } \\
\text { To what extent } \\
\text { do you agree } \\
\text { with }\end{array}$ & Strongly disagree and disagree & $\begin{array}{l}\text { Agree } \\
\text { and } \\
\text { strongly agree }\end{array}$ & r & $p$ \\
\hline $\begin{array}{l}\text { Official media } \\
\text { like People's } \\
\text { Daily and Global T }\end{array}$ & 9. 59\% & 72. $06 \%$ & 0.424 & .000 \\
\hline $\begin{array}{l}\text { Health and } \\
\text { medical bloggers } \\
\text { on MicroBlog/ } \\
\text { WeChat/ TikTok }\end{array}$ & $10.41 \%$ & $67.67 \%$ & 0.406 & .000 \\
\hline $\begin{array}{l}\text { Information not } \\
\text { confirmed by the } \\
\text { official press }\end{array}$ & $1.37 \%$ & $62.74 \%$ & 0.256 & .000 \\
\hline $\begin{array}{l}\text { Keep an eye on } \\
\text { the epidemic } \\
\text { information }\end{array}$ & $9.68 \%$ & $90.14 \%$ & 0.540 & .000 \\
\hline
\end{tabular}




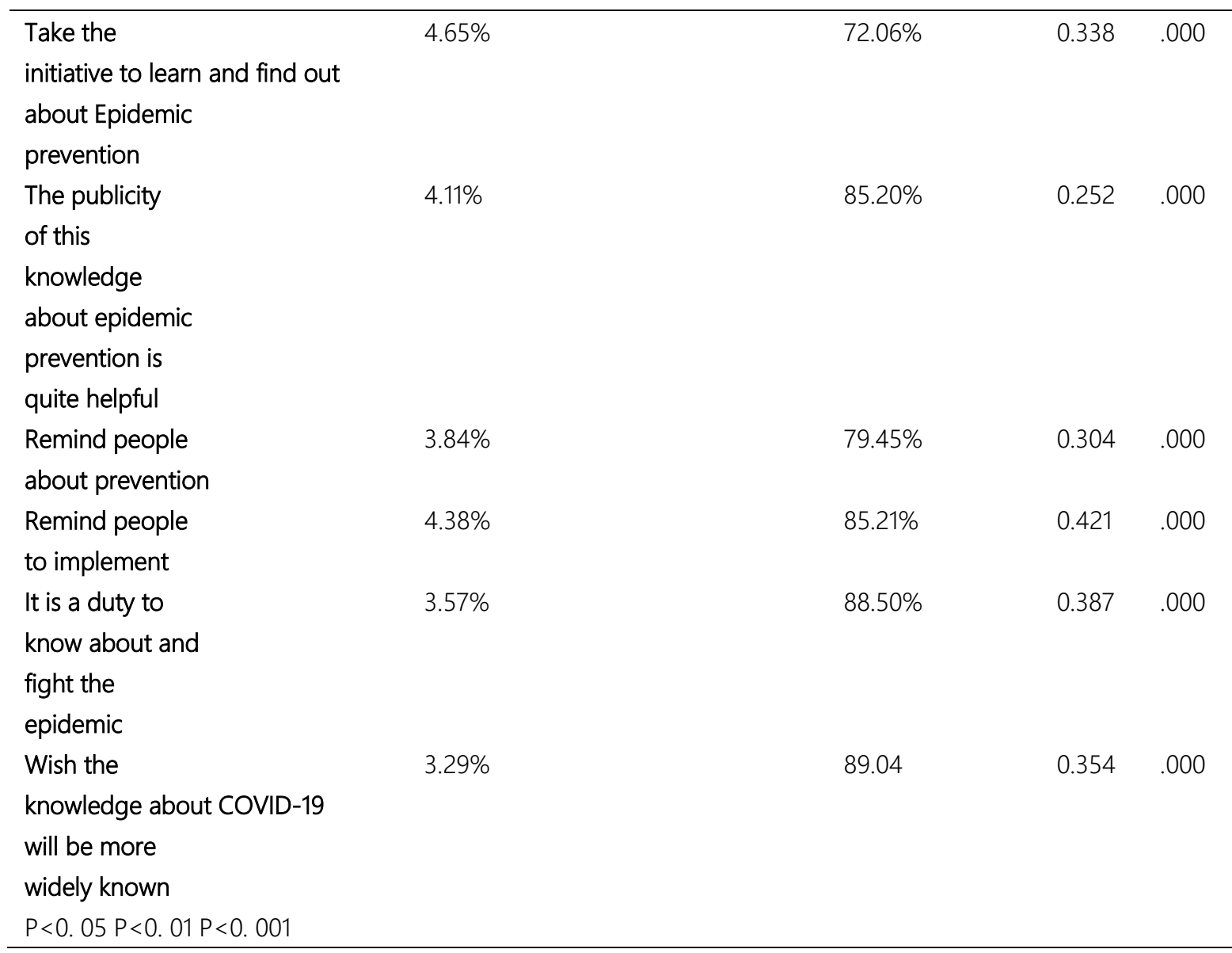

Using Pearson's correlation coefficient analysis, the results of the study showed that people who paid attention to epidemic prevention information released by official media like People's Daily and Global Times $(r=0.424$, $\mathrm{P}=0.000<0.001) ; \quad$ liking/commenting/re-tweeting epidemic prevention information released by health and medical bloggers with a high number of followers on Micro-Blog/ We-Chat/ Tik Tok ( $\mathrm{r}=0.406$, $\mathrm{P}=0.000<0.001$ ); to the information on epidemic prevention that is not confirmed by the official press, the attitude is that it is better to believe it than not ( $\mathrm{r}=0.256$, $\mathrm{P}=0.000<0.001$ ); paying attention to epidemic prevention information in real time during an outbreak $(r=0.540$, $\mathrm{P}=0.000<0.001$ ); taking the initiative to understand and find out about epidemic prevention $(\mathrm{r}=0.338$, $\mathrm{P}=0.000<0.001)$; thinking that the dissemination and popularization of such epidemic prevention knowledge is helpful for everyone $(\mathrm{r}=0.252, \quad \mathrm{P}=0.000<0.001)$; reminding their friends and relatives to pay attention to and learn about epidemic prevention $(r=0.304$,
$\mathrm{P}=0.000<0.001$ ); reminding their relatives and friends to pay attention to and learn about epidemic prevention $(\mathrm{r}=0.421, \quad \mathrm{P}=0.000<0.001)$; reminding friends and relatives to implement epidemic prevention measures such as reminding people to wear masks, washing hands regularly, etc. $(\mathrm{r}=0.421, \mathrm{P}=0.000<0.001)$; considering that it is my responsibility and obligation to learn about epidemic prevention and take precautions $(\mathrm{r}=0.387$, $\mathrm{P}=0.000<0.001$ ); and hoping that knowledge about epidemic prevention should be better understood by more people $(\mathrm{r}=0.354, \mathrm{P}=0.000<0.001)$ have a prominence positive correlation with citizens' adoption of epidemic prevention behavior. As a result, the more citizens are concerned about epidemic prevention knowledge and the more positive their attitudes are, the more likely they are to adopt epidemic prevention behavior. Therefore, the original hypothesis is valid.

\subsection{Hypothesis 3}

Table 3. Data coding for hypothesis 3

\begin{tabular}{lllll}
\hline $\begin{array}{l}\text { Title: } \\
\begin{array}{l}\text { To what extent } \\
\text { do you agree }\end{array}\end{array}$ & Strongly disagree and disagree & $\begin{array}{l}\text { Agree } \\
\text { and } \\
\text { with }\end{array}$ & strongly agree & \\
\hline friends and & $3.57 \%$ & $73.70 \%$ & 0.512 & .000
\end{tabular}




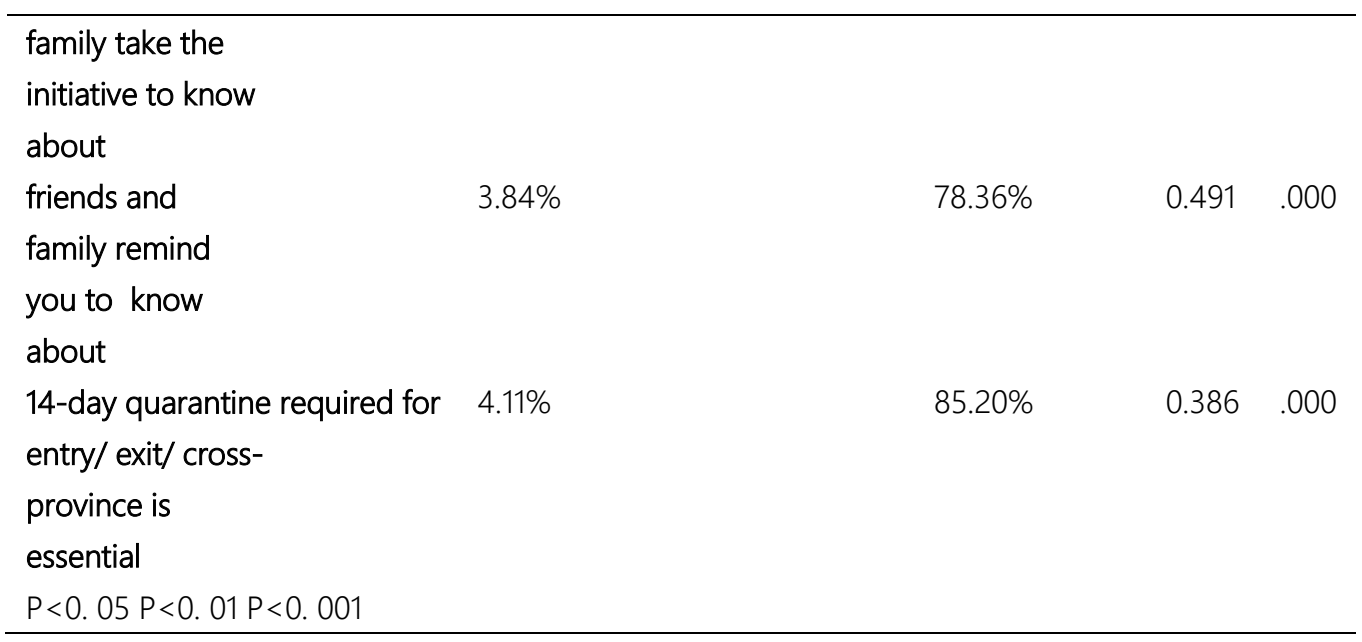

Using Pearson's correlation coefficient analysis, the results of the study indicates that friends and relatives take the initiative to learn and find out about epidemic prevention $(\mathrm{r}=0.512, \quad \mathrm{P}=0.000<0.001)$; friends and relatives believe they should pay attention to epidemic prevention information proactively $(\mathrm{r}=0.491$, $\mathrm{P}=0.000<0.001)$; the need to quarantine for 14 days during an epidemic $(r=0.386$, test $\mathrm{P}=0.000<0.001)$ have a striking positive correlation with citizens' adoption of epidemic prevention behavior. In conclusion, citizens' friends' and relatives' concern for epidemic prevention information has a notable impact on citizens' willingness to adopt epidemic prevention measures. As a result, the original hypothesis was valid.

\section{DISCUSSION}

To study the impact of Health Communication on the prevention and control behavior and awareness effects of Shanghai residents in the context of the new crown epidemic. The analysis is as follows.

Hypothesis 1 holds, in this study, that the degree of exposure to knowledge about epidemic prevention corresponds to the behavioral control perception factor of the Theory of Planned Behavior. The ease of exposure to knowledge about epidemic prevention has a significant effect on citizens' adoption of epidemic prevention behavior. The data analysis suggests that if a citizen is in an environment where the one is regularly exposed, consciously or unconsciously, to learning of epidemic prevention, the more and more frequently he is exposed to the information, the more likely he is to adopt epidemic prevention behavior. From a Health Communication point of view, to achieve universal epidemic prevention, it is possible to increase the number of points of information about epidemic prevention within the citizens' sphere of activity. The citizens' knowledge of epidemic prevention is implicitly imprinted in their minds. These are all outstanding and practical ways to promote awareness of epidemic prevention and to further the goal of epidemic prevention for all.
Hypothesis 2 holds, in this study, that citizens' attitudes and interest in knowledge about epidemic prevention correspond to the attitude factor in the Theory of Planned Behavior. The study shows that citizens' active interest in information about epidemic prevention has a significant impact on citizens' adoption of epidemic prevention behavior. The data analysis suggests that if a citizen has a positive attitude towards collecting information on epidemic prevention, this will increase the level of interest in information on epidemic knowledge and thus promote the adoption of epidemic prevention behaviors by citizens. From a Health Communication perspective, positive attitudes towards citizens' knowledge of epidemic prevention can be improved in the following ways. One is innovation in the form of communication. When most people are far more dependent on mobile phones than television and newspapers, and meanwhile, with the advent of the Internet era and the rise of short video software, epidemic prevention knowledge can be promoted through this channel. The other one is innovation in publicity content. The characters and language in the advertisements can resonate with the citizens so that they can pay more attention to the information on epidemic prevention and achieve the goal of epidemic prevention for all.

Hypothesis 3 holds, in this study, that the level of concern of citizens' friends and relatives for information on epidemic prevention corresponds to the subjective norms factor in the Theory of Planned Behavior, which examines how external factors influence citizens' adoption of epidemic prevention measures. There are two main types of external factors: citizens' social relations and the other being moral norms. The data analysis illustrates that the social pressure on the city also has a significant impact on the adoption of preventive behavior. From a Health Communication perspective, friends and family reminding citizens about epidemic prevention, the government mandating passengers to wear masks when travelling on public transport in China and the mandatory 14-day quarantine when entering, leaving or coming from high-risk areas are all examples 
of external social pressure on citizens. In this way, residents will regard adopting epidemic prevention behavior as part of their moral code. Accordingly $88.5 \%$ of people in the questionnaire consider themselves to be responsible and obliged to perform epidemic prevention acts. In some provinces and cities in China, there is currently a proposal to legislate specifically for wearing masks, which would make it easier to promote universal epidemic prevention.

In line with the literature, Health Communication can positively effect epidemic control to some extent. The study also addresses cities with excellent epidemic prevention and control. It fills a gap in the existing literature by exploring the reasons for Shanghai's superior epidemic prevention and control and the factors influencing it. In addition, the study finds that the majority of Shanghai residents trust the news released by official channels and do not trust in the articles on WeChat or Micro-Blog as much. Moreover, regardless of whether the epidemic prevention information is published in the paper, online media, or short video selfpublished media, any information published through the unofficial public press, in comparison, was less effective than information published through official channels. This is most likely related to the average level of education of Shanghai residents. Because of the higher average level of educational quality, they can recognize rumors as they reserve their opinions and do not trust any information released unofficially, and only trust statements released officially.

Based on the Theory of Planned Behaviour, the main variables are attitudes towards collecting information on epidemic prevention, the interest of friends and family in collecting information on epidemic prevention and the ease of access to information on epidemic prevention. These determine the effect of health communication on the prevention and control behaviour and awareness of Shanghai residents in the context of the COVID-19. The more positive a person's attitude towards collecting epidemic prevention information, the more friends and relatives around them are concerned about epidemic prevention information, and the easier it is to learn about epidemic prevention information, the more likely he is to adopt epidemic prevention behaviour, and the less likely he is to do otherwise. This is a lesson that can be replicated in other countries concerning the need for vaccination.

\section{CONCLUSION}

This report presents a study on the effect of health communication on the prevention and control behaviour and awareness effects of Shanghai residents in the new crown epidemic, using a questionnaire approach. Hypothesis 1 is valid, corresponding to the behavioral perceptual control factor in the Theory of Planned Behaviour.It depicts that a Shanghai resident is more likely to adopt epidemic prevention and control behaviour if that person is easier to collect epidemic prevention and control information. Therefore, enhancing the frequency with which residents receive epidemic prevention information will improve the effectiveness of epidemic prevention in the area. Hypothesis 2 is valid and corresponds to the attitudinal factor in the Theory of Planned Behaviour. It describes residents who are more proactive in following epidemic prevention information will also positively effect the epidemic prevention effectiveness of the area. Therefore, the statement released by the official media can take a more innovative media approach to attract people's attention. Hypothesis 3 is valid, which corresponds to the subjective normative factor in the Theory of Planned Behaviour. It reveals that the more people in the area feel pressured by their friends and family or by society, the more they will pay attention to epidemic prevention information and thus adopt epidemic prevention behaviour. Therefore, the government's enactment of laws and regulations to prevent epidemics, such as the wearing of masks, will have a significant impact on the effectiveness of epidemic prevention in the area. In summary, by using the Theory of Planned Behaviour, these three factors could be applied to other epidemic prevention measures in worldwide.

\section{REFERENCES}

[1] Le T K , Paris C, Khan K S, et al. Nucleic acidbased technologies targeting corona-virusesScience Direct [J]. 2020.

[2] Alvarez-Hernandez L R, Cardenas I, Bloom A. COVID-19 Pandemic and Intimate Partner Violence: an Analysis of Help-Seeking Messages in the Spanish-Speaking Media [J]. Journal of Family Violence, 2021:1-12.

[3] D. M. Li, P. P. Wen, Y. J. Xv, et al. Analysis of the impact of media propaganda on infectious disease control $[\mathrm{J}]$. Journal of Harbin University of Technology, 2015, 020(006):112-118.

[4] W. T. Duan, G. G. Jiang. A review of the theory of planned behavior $[\mathrm{J}]$. Advances in Psychological Science, 2008, 16(2):315-320.

[5] Rogers E M. The field of health communication today: an up-to-date report [J]. Journal of Health Communication, 1996, 1(1):15-23.

[6] Wolinsky. The sociology of health [M]. Published by Social Science Literature Press, 1992.

[7] Y. Yan. Research on the communication effect of health public numbers in the context of epidemictaking university students' group as an example [J]. China Press, 2021(02):19-21. 
[8] State Council. National emergency response plan for public emergencies [J]. Chinese Journal of Basic Chinese Medicine, 2006(1).

[9] Card S K, Mackinlay J D, Shneiderman B. Readings in Information Visualization: Using Vision To Think $[\mathrm{M}]$. Morgan Kaufmann Publishers Inc. 1999.

[10] B. Tong. Information disclosure and the cathartic function of the media in sudden public events [J]. Nanjing Social Science, 2009, 000(008):37-44.

[11] Das Anupam Kumar et al. Fighting ahead: Adoption of social distancing in COVID-19 outbreak through the lens of theory of planned behavior [J]. Journal of Human Behavior in the Social Environment, 2021, 31 (1-4), pp. 373-393.

[12] Bulmer M. Sociological research methods: [M]. Macmillan, 1977. 